\title{
Electrochemical Synthesis of Octahedral Nanostructured $\mathrm{PbF}_{2}$
}

\author{
Joon Ho Lee and Jinsub Choi ${ }^{\dagger, *}$ \\ Department of Textile Engineering, Inha University, Incheon 402-751, Korea \\ ${ }^{\dagger}$ Department of Chemical Engineering, Inha University, Incheon 402-751, Korea. *E-mail: jinsub@inha.ac.kr \\ Received August 3, 2010, Accepted November 29, 2010
}

\begin{abstract}
In this work, we investigate anodization of $\mathrm{Pb}$ in ethylene glycol containing small amount of $\mathrm{NH}_{4} \mathrm{~F}$, demonstrating that $\beta-\mathrm{PbF}_{2}$ particles with octahedral morphology can be prepared by adjusting the applied potential and anodizing time. FE-SEM images and XRD measurements of anodic nanostructures as a function of anodizing time clearly show that $\mathrm{PbO}$ is first formed on $\mathrm{Pb}$. Subsequently, a local dissolution of $\mathrm{PbO}$ leads to formation of skeleton structure of $\mathrm{PbO}$, releasing $\mathrm{Pb}^{2+}$ ions in the electrolyte. The lead ions can be precipitated on the walls or intersection of the skeleton walls when the concentration of lead ions is saturated. The method described in this article shows the feasibility of formation of metal fluoride crystal by anodization of metal in a fluoride containing solution.
\end{abstract}

Key Words: Anodization, $\mathrm{Pb}$ foil, Lead oxide, Octahedral structure, Superionic

\section{Introduction}

Lead fluoride is one of important metal fluorides that are possibly used for a various range of electrical and optical applications. Lead fluoride exists in two phases, e.g., $\alpha-\mathrm{PbF}_{2}$ and $\beta-\mathrm{PbF}_{2}$, and the phases can be reversibly converted to each other by adjusting heating temperature and pressure. ${ }^{1}$ In orthorhombic $\alpha-\mathrm{PbF}_{2}$, each lead ion is centered at nine fluoride ions at different distances, making a distorted close packing of fluoride ions. For the cubic $\beta-\mathrm{PbF}_{2}$, each lead ion is surrounded by eight fluoride ions, which are accommodated at the corners of a surrounding cube. ${ }^{2}$

It has been demonstrated that $\alpha-\mathrm{PbF}_{2}$ is a strong scintillator that can be used as a detector in electromagnetic calorimeter and $\beta-\mathrm{PbF}_{2}$ is a superionic conductor that can be used as a solid electrolyte in $\mathrm{Li}$ ion batteries. ${ }^{3,4}$

To the best of our knowledge, there are no many reports on the preparation of nanostructured $\mathrm{PbF}_{2}$. Stubičar et al. showed that $\alpha-\mathrm{PbF}_{2}$ can be prepared by supersaturation of $\mathrm{Pb}\left(\mathrm{NO}_{3}\right)_{2}$ and $\mathrm{KF}$ and it can be decomposed into $\beta-\mathrm{PbF}_{2}$ by annealing at $450{ }^{\circ} \mathrm{C}$. . Thangadurai et al. showed that orthorhombic $(\alpha)$ and cubic $(\beta) \mathrm{PbF}_{2}$ can be synchronically prepared by an inert gas condensation technique under ultra-high vacuum. ${ }^{6}$ Subsequently, the annealing of the sample leads to the conversion of $\alpha-\mathrm{PbF}_{2}$ into $\beta-\mathrm{PbF}_{2}$, resulting in the preparation of $\beta-\mathrm{PbF}_{2}$ dominant phase. $\mathrm{Xu}$ et al. demonstrated that $\alpha-\mathrm{PbF}_{2}$ nanorods can be prepared via a sonochemical route in microemulsion system and the structure exhibits strong green emission. ${ }^{7}$ More recently, $\mathrm{Xu}$ has showed that octahedral $\mathrm{PbF}_{2}$ can be produced by the sonochemical method based on oriented attachment process. ${ }^{8}$ More recently, Zhu et al. have demonstrated that $\beta-\mathrm{PbF}_{2}$ microsphere and $\alpha-\mathrm{PbF}_{2}$ microrods with different size can be controllably fabricated by hydrothermal methods. ${ }^{2}$

Anodization technique is based on an electrolytic passivation process that allows increasing the thickness of natural oxide formed on the metal surface, resulting in the formation of corrosion and/or wear resistive oxide. Recently, several groups demonstrated that self-ordered nanoporous oxides can be prepared on various metals such as aluminum, titanium, zirconium, niobium and so on by anodization techniques. ${ }^{9-12}$ In addition, our group showed that self-assembled nanostructures, e.g., lamella structures and nanowires, can be produced by anodization of metals under controlled electrochemical conditions. For example, if zinc is anodized in an electrolyte containing fluoride ions, $\mathrm{ZnF}_{2}$ nanowires or $\mathrm{ZnO}$ pattern can be selectively prepared in terms of electrochemical conditions. ${ }^{13}$

According to the literatures, anodization of a lead foil in sulfuric acid leads to prepare $\mathrm{Pb} / \alpha-\mathrm{PbO} / \mathrm{PbSO}_{4}$ membrane at low potential ranges. In the case of high potential ranges, $\mathrm{PbO}_{2}$ layer can be produced at the interface between $\alpha-\mathrm{PbO}$ and $\mathrm{PbSO}_{4}$, which are originated from both the $\alpha-\mathrm{PbO}$ layer and the $\mathrm{PbSO}_{4}$ membrane. ${ }^{14}$ Dense $\mathrm{PbO}$ or $\mathrm{PbO}_{2}$ without the sulfate membrane can be produced by anodization of $\mathrm{Pb}$ in various alkali electrolytes. $^{15,16}$

In this article, we describe for the first time that well-defined octahedral $\mathrm{PbF}_{2}$ can be obtained by electrochemical oxidation of a $\mathrm{Pb}$ foil in an ethylene glycol electrolyte containing $\mathrm{NH}_{4} \mathrm{~F}$. This shows the possibility that anodization technique can produce useful metal fluoride crystal with controllable shapes.

\section{Experimental}

$0.25-\mathrm{mm}$ thick $\mathrm{Pb}$ foils with a purity of $99.99 \%$ were purchased from Goodfellow, UK. Before anodization, the lead foils were cleaned with acetone in an ultrasonic bath for $5 \mathrm{~min}$. Subsequently, they were washed with ethanol and dried with a stream of $\mathrm{N}_{2}$ gas. Then, the specimens were anodized in an ethylene glycol (EG) electrolyte containing $\mathrm{NH}_{4} \mathrm{~F}$ at room temperature at different potentials from $1 \mathrm{~V}$ to $20 \mathrm{~V}$ for different anodizing times, using a power supply (SourceMeter 2400, Keithley) interfaced to a computer. Note that all electrolytes were prepared from reagent-grade chemicals (Aldrich) and deionized water (DI water, $>18 \mathrm{M} \Omega \mathrm{cm}$ ).

The cell was a two-electrode system consisting of a Pt mesh acting as the counter electrode, and the lead foil as the working electrode. During the anodization, the stirring speed was kept 
constant $(\approx 180 \mathrm{rpm})$.

The morphology and composition of nanostructures formed on lead surface were characterized by a field emission scanning electron microscope (FE-SEM, JSM 6700F, JEOL, Japan), operated at an accelerating voltage of $15 \mathrm{kV}$. Before FE-SEM measurements, the air-dried samples were first coated with a Pt layer by a sputter coater (108 auto sputter coater, Cressington Scientific Instruments, USA). The crystallinity and composition of the nanostructures were characterized by a X-ray diffractometer (XRD, Phillips DY616).

\section{Results and Discussion}

Fig. 1 shows morphological changes of nanostructures formed on $\mathrm{Pb}$ foils as a function of applied potentials. As shown in Fig. 1 (a) and (b), a distinct shape is not observed at $1 \mathrm{~V}$, whereas nanostructures with a narrow size distribution are exhibited at $2 \mathrm{~V}$. The enlarged view of Fig. 1 (b) reveals that the nanostructures have truncated octahedral morphologies and they are likely not fully grown. As the potential increases, well-defined octahedral structures are clearly observed (Fig. 1 (c), (d) and (e)). Broad size distributions of octahedral structures are observed when the potential increases. Finally, a mixture of octahedral structures with a size of larger than $1 \mu \mathrm{m}$ and of around $100 \mathrm{~nm}$ is obtained at $20 \mathrm{~V}$ as shown in Fig. 1 (F). The large octahedral structures are probably originated from the aggregation of the small ones, meaning that lead ions rejected from the positively biased surface and anions $\left(\mathrm{F}^{-}\right)$attracted to the $\mathrm{Pb}$ metal precipitate near the surface. Such potential-dependent morphologi-

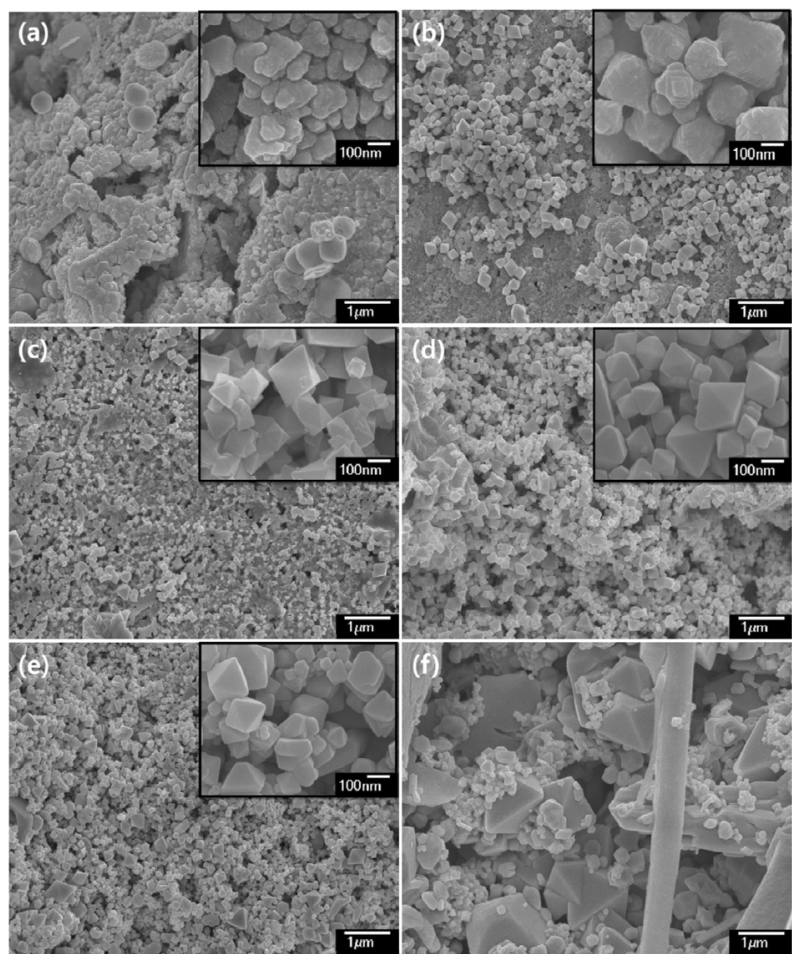

Figure 1. FE-SEM images of nanostructures formed on a $\mathrm{Pb}$ foil by anodization in ethylene glycol containing $1 \mathrm{wt} \% \mathrm{NH}_{4} \mathrm{~F}\left(\mathrm{EG}+\mathrm{NH}_{4} \mathrm{~F}\right)$ for $60 \mathrm{~min}$ at $30^{\circ} \mathrm{C}$ at different potentials: (a) $1 \mathrm{~V}$, (b) $2 \mathrm{~V}$, (c) $3 \mathrm{~V}$, (d) $5 \mathrm{~V}$, (e) $10 \mathrm{~V}$, and (f) $20 \mathrm{~V}$. cal changes are probably due to the degree of dissolution of $\mathrm{Pb}$ ions and their precipitation. In other words, large amount of $\mathrm{Pb}$ ions dissolved from $\mathrm{Pb}$ metal are released at high potential, making a high possibility of precipitation because of a limited solubility near the surface.

In order to investigate a growth mechanism of the octahedral structures in detail, anodization was carried out at $5 \mathrm{~V}$ for different anodizing times. Interestingly, if anodization is performed for very short time, skeleton of walls consisting of several planes perpendicular to each others are produced as shown in Fig. 2 (a). The skeleton structures are attributed to etching of the metal surface. At the initial stage, the positively biased metal is attacked by anions, resulting in the formation of etched surface. As anodization goes on, the skeleton structures are covered with deposits, resulting in the preparation of truncated octahedral particles (see Fig. 2 (b)). We can observe the skeleton structures underneath the truncated octahedral particles (not shown here). Probably, the wall and intersection of wall in the skeleton structures can play a role as the seeding sites for the growth of the truncated octahedral particles. The well-defined octahedral structures are obtained when anodization is carried out for $60 \mathrm{~min}$ (see Fig. 2 (c)). The further anodization time leads to the formation of huge octahedral structures that are partially embedded in the ground (Fig. 2 (d)).

Of course, the formation velocity of octahedral particles is enhanced when the applied potential increases. Note that a mixture of octahedral particles with a large $(>1 \mu \mathrm{m})$ and small size $(\sim 100 \mathrm{~nm})$ is obtained within $60 \mathrm{~min}$ at $20 \mathrm{~V}$ (Fig. 1 (f)), whereas in 300 min at $5 \mathrm{~V}$ (Fig. 2 (d)).

Fig. 3 (a), (b), and (c) show the XRD results of the nanostructures shown in Fig. 2 (a), (b) and (c), respectively. It strongly suggests that Fig. 2 (a) mainly consists of $\mathrm{PbO}$. Note that the $\mathrm{Pb}$ peaks originate from the $\mathrm{Pb}$ substrate. As the anodization is carried out for more than $15 \mathrm{~min}, \beta-\mathrm{PbF}_{2}$ peaks are strongly detected (see the $\beta-\mathrm{PbF}_{2}$ peak in Fig. 3 (b)). Thus, the skeleton structures and octahedral structures are $\mathrm{PbO}$ and $\beta-\mathrm{PbF}_{2}$, respectively. As shown in Fig. 3 (c), several $\mathrm{PbO}_{2}$ peaks disappear

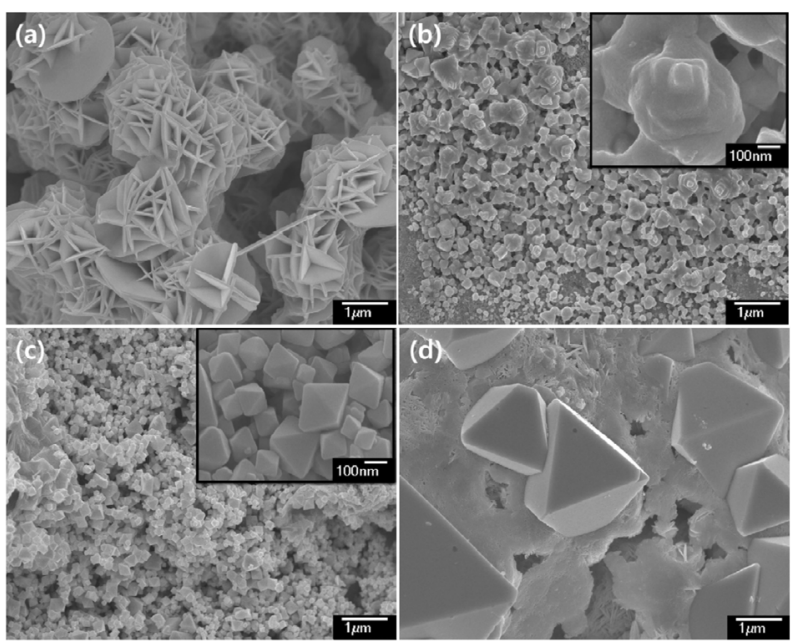

Figure 2. FE-SEM images of anodization of $\mathrm{Pb}$ foil in $\mathrm{EG}+\mathrm{NH}_{4} \mathrm{~F}$ at $5 \mathrm{~V}$ at $30{ }^{\circ} \mathrm{C}$ for different anodizing times: (a) $5 \mathrm{~min}$, (b) $15 \mathrm{~min}$, (c) $60 \mathrm{~min}$, and (d) $300 \mathrm{~min}$. 


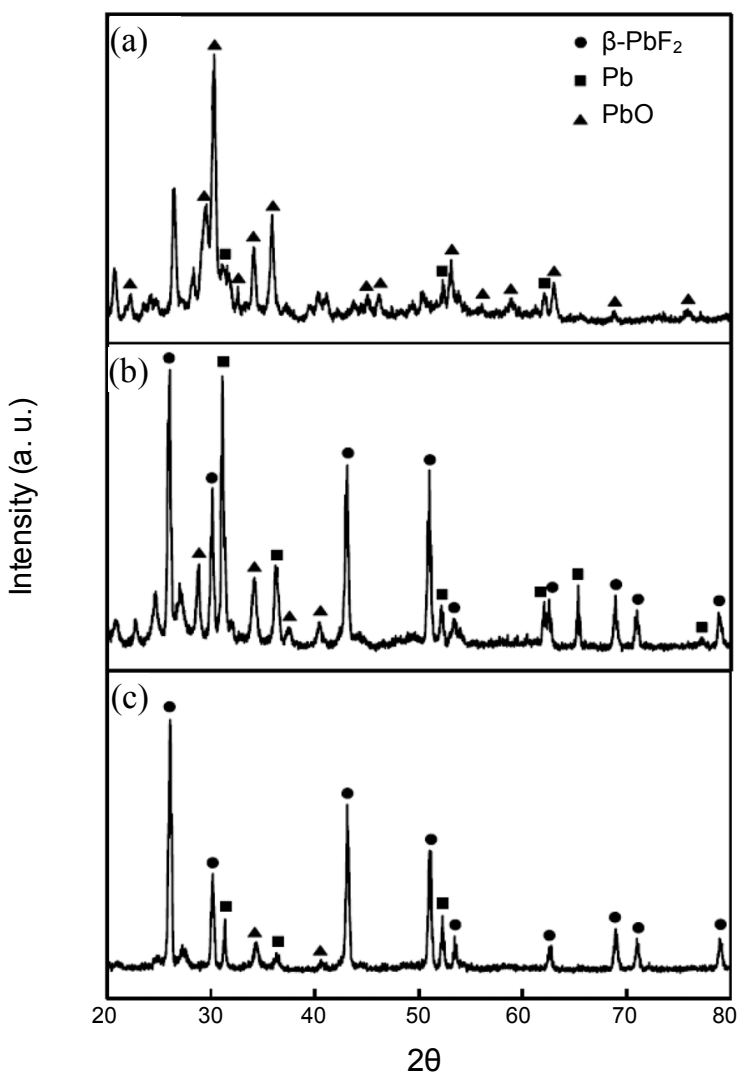

Figure 3. $\mathrm{XRD}$ data of anodization of $\mathrm{Pb}$ foil in $\mathrm{EG}+\mathrm{NH}_{4} \mathrm{~F}$ at $5 \mathrm{~V}$ at $30^{\circ} \mathrm{C}$ for different anodizing times: (a) $5 \mathrm{~min}$, (b) $15 \mathrm{~min}$, and (c) $60 \mathrm{~min}$. Fig. 3 (a), (b), and (c) correspond to the XRD data of Fig. 2 (a), (b), and (c), respectively.

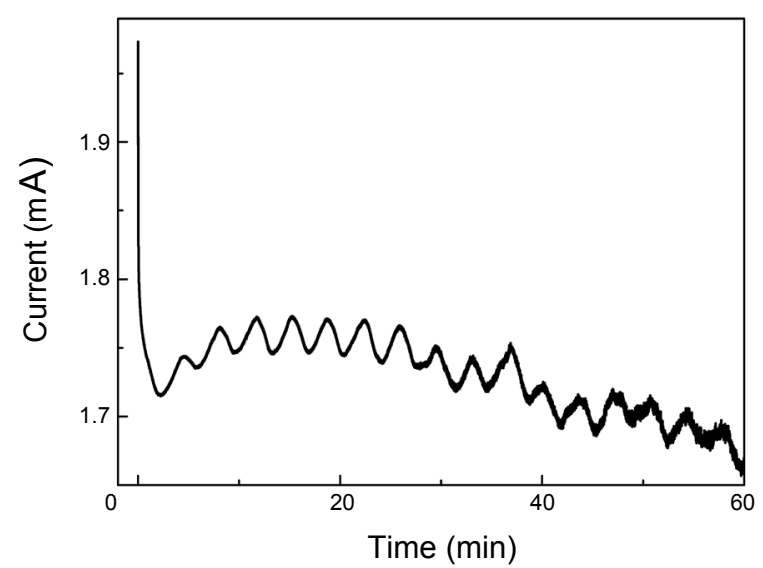

Figure 4. Time-current transients during anodization of $\mathrm{Pb}$ in $\mathrm{EG}+$ $\mathrm{NH}_{4} \mathrm{~F}$ for 60 min at $5 \mathrm{~V}$ at $30^{\circ} \mathrm{C}$.

and $\beta-\mathrm{PbF}_{2}$ peaks appear as anodization is carried out for longer time.

Fig. 4 shows typical current-time transient during anodization, exhibiting that current is periodically oscillated. Note that it is shown in other potential ranges where the $\mathrm{PbF}_{2}$ is formed. This strongly suggests that dissolution and precipitation occur near the surface during the anodization. Because of positive bias, $\mathrm{Pb}$ is oxidized into $\mathrm{PbO}:^{17}$ (a)

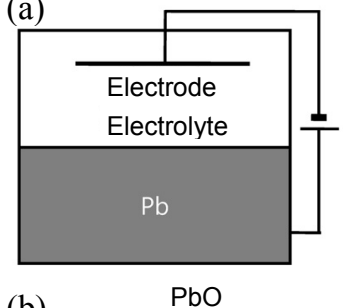

(b)
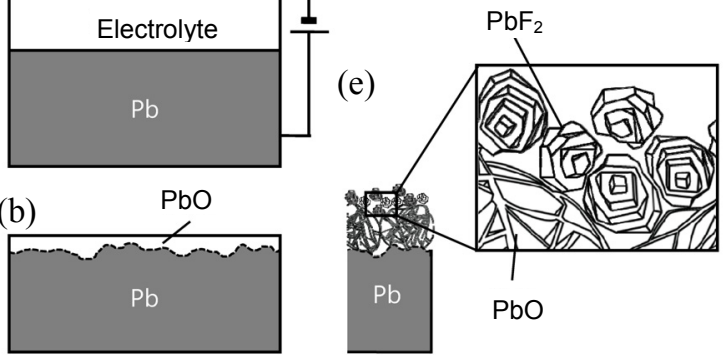

(c)

$\mathrm{PbO}$
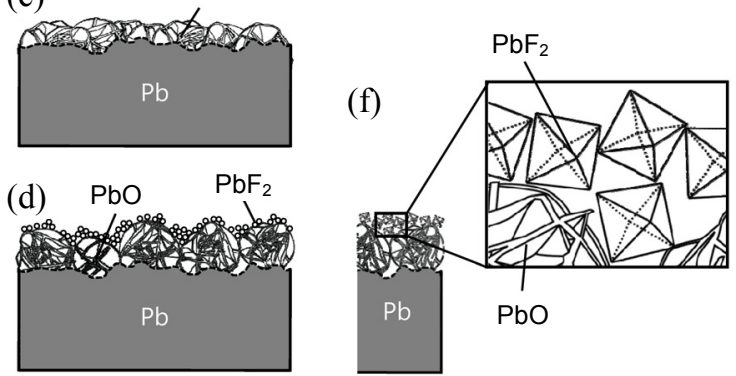

Figure 5. Schematic diagram of mechanism of $\mathrm{PbF}_{2}$ formation during anodization. (a) raw $\mathrm{Pb}$ foil, (b) formation of $\mathrm{PbO}$ and local dissolution of $\mathrm{PbO}$, (c) formation of skeleton structures as a result of local etching of $\mathrm{PbO}$, (d) precipitation of lead ions and fluoride ions, resulting in the formation of $\mathrm{PbF}_{2}$, (e) formation of $\mathrm{PbF}_{2}$ with a truncated octahedral morphology, and (f) full development of $\mathrm{PbF}_{2}$ with octahedral morphology.

$$
\mathrm{Pb}^{2+}+2 \mathrm{OH}^{-} \rightarrow \mathrm{Pb}(\mathrm{OH})_{2}
$$

$$
\mathrm{Pb}(\mathrm{OH})_{2} \rightarrow \mathrm{PbO}+\mathrm{H}_{2} \mathrm{O}
$$

Since $\mathrm{F}^{-}$ions can substitute hydroxide or oxygen sites, ${ }^{18}$ anodization in the solution containing $\mathrm{F}^{-}$ions may lead to the breakdown of the bonds of $\mathrm{Pb}-(\mathrm{OH})_{2}$ or $\mathrm{Pb}-\mathrm{O}$, resulting in the local etching of $\mathrm{PbO}$.

$$
\begin{aligned}
& \mathrm{PbO} \rightarrow \mathrm{Pb}^{2+}+\mathrm{O}^{2-} \\
& \mathrm{Pb}(\mathrm{OH})_{2} \rightarrow \mathrm{Pb}^{2+}+2 \mathrm{OH}^{-}
\end{aligned}
$$

This gives $\mathrm{OH}^{-}$rich environmental near the $\mathrm{PbO}$ film. Because dissolution of $\mathrm{PbO}$ in the electrolyte is enhanced when the $\mathrm{pH}$ increases, ${ }^{19}$ the dissolution of $\mathrm{PbO}$ is locally enhanced, making the skeleton structures as shown in Fig. 2 (a).

As the $\mathrm{Pb}^{2+}$ concentration increases in the solution, the possibility of precipitation of $\mathrm{Pb}^{2+}$ and $\mathrm{F}^{-}$increases. The precipitation can easily occur at the seeding points that are the wall and the intersection of walls in the skeleton structures.

$$
\mathrm{Pb}^{2+}+2 \mathrm{~F}^{-} \rightarrow \mathrm{PbF}_{2}
$$


Mechanism of formation of $\mathrm{PbF}_{2}$ on $\mathrm{PbO}$ is depicted in Fig. 5. $\mathrm{A}$ raw $\mathrm{Pb}$ foil with flat surface is anodized into the formation of $\mathrm{PbO}$ film (Fig. 5 (a) and (b)). The PbO film is locally etched, resulting in the formation of skeleton structures (Fig. 5 (c)). Further etching of $\mathrm{PbO}$ films leads to increase the concentration of $\mathrm{Pb}^{2+}$ ions near the skeleton structures, causing to precipitation of $\mathrm{Pb}^{2+}$ at the location of wall and intersection of wall in the skeleton (Fig. 5 (d)). The deposits by the precipitation of $\mathrm{Pb}^{2+}$ and $\mathrm{F}^{-}$are grown into truncated octahedral particles (Fig. 5 (e)), finally leading to the formation of octahedral particles (Fig. 5 (f)).

\section{Conclusions}

We demonstrated that anodic oxidation of a $\mathrm{Pb}$ foil can lead to produce octahedral particles formed on the skeleton of $\mathrm{PbO}$, which is as a result of oxidation of $\mathrm{Pb}$ and subsequent local dissolution of $\mathrm{PbO}$ due to the $\mathrm{F}^{-}$ions. FE-SEM images and $\mathrm{XRD}$ data clearly confirm that skeleton structures mainly consist of $\mathrm{PbO}$ which is observed before anodization for $15 \mathrm{~min}$ (at $5 \mathrm{~V}$ ). On the other hand, octahedral particles that are mainly composed of $\beta-\mathrm{PbF}_{2}$ start to appear when anodization is carried out for longer than $15 \mathrm{~min}$.

Effect of applied potentials on the morphology of $\mathrm{PbF}_{2}$ was investigated, showing that no distinct morphology is shown at low potential ranges. On the other hand, more distinct octahedral structure is observed as the potential increases. If the potential is high as much as $20 \mathrm{~V}$, small octahedral structures merge together, making a mixture of a large size $(>1 \mu \mathrm{m})$ and small size $(\sim 100 \mathrm{~nm})$ octahedral structures. If the growth time is sufficient, the size of octahedral particles increases due to the combination of the small particles. The results provide a simple method for the formation of metal fluoride crystals by anodization of metal. We believe that it can probably be applied for other metals.
Acknowledgments. This research was supported by the Basic Research Program through the National Research Foundation of Korea (NRF) and funded by the Ministry of Education, Science and Technology (2010-0011197).

\section{References}

1. Samara, G. A. J. Phys. Chem. Solids 1979, 40, 509.

2. Zhu, G.; Liu, P.; Hojamberdiev, M.; Zhou, J.-p.; Huang, X. J. Mater. Sci. 2010, 45, 1846.

3. Wang, F.; Grey, C. P. J. Am. Chem. Soc. 1995, 117, 6637.

4. Alov, D. L.; Rybchenko, S. I. J. Phys. Condens. Matter. 1995, 7, 1475.

5. Stubičar, N.; Marković, B.; Tonejc, A.; Stubičar, M. J. Cryst. Growth 1993, 130, 300

6. Thangadurai, P.; Ramasamy, S.; Kesavamoorthy, R. J. Phys. Condens. Matter 2005, 17, 863.

7. Xu, K.; Mao, C.; Geng, J.; Zhu, J. J. Nanotechnology 2007, 18, 315604.

8. Xu, K. Mater. Lett. 2008, 62, 4322.

9. Choi, J.; Wehrspohn, R. B.; Lee, J.; Gösele, U. Electrochim. Acta 2004, 49, 2645.

10. Macak, J. M.; Tsuchiya, H.; Schmuki, P. Angew. Chem. Int. Ed. 2005, 44, 2100.

11. Tsuchiya, H.; Schmuki, P. Electrochem. Commun. 2004, 6, 1131.

12. Choi, J.; Lim, J. H.; Lee, S. C.; Chang, J. H.; Kim, K. J.; Cho, M. A. Electrochim. Acta 2006, 51, 5502.

13. Kim, S. J.; Lee, J.; Choi, J. Electrochim. Acta 2008, 53, 7941.

14. Pavlov, D.; Diner, Z. J. Electrochem. Soc. 1980, 127, 855.

15. Veluchamy, P.; Sharon, M.; Minoura, H.; Ichihashi, Y.; Basavaswaran, K. J. Electroanal. Chem. 1993, 344, 73.

16. Veluchamy, P.; Minoura, H. Appl. Phys. Lett. 1993, 65, 2431.

17. EL-Naggar, M. M. J. Power. Source 2004, 126, 207.

18. Cao, J. ; Zhao, H.; Cao, F.; Zhang, J. Electrochim. Acta 2007, 52 , 7870.

19. Yurkinskii, V. P.; Sokolova, N. V.; Popov, V. A. Russian J. Appl. Chem. 2001, 74, 427. 